\title{
Galectin-1 Promotes Metastasis in Gastric Cancer Through a Sphingosine- 1-Phosphate Receptor 1-Dependent Mechanism
}

\author{
Xiaolan You ${ }^{\mathrm{a}, \mathrm{b}}$ Yuanjie Wang ${ }^{\mathrm{b}}$ Jian Wu $\mathrm{W}^{\mathrm{b}}$ Qinghong Liu ${ }^{\mathrm{b}}$ Dehu Chen ${ }^{\mathrm{b}}$ \\ Dong Tang ${ }^{c}$ Daorong Wang ${ }^{c}$
}

\begin{abstract}
aDepartment of Integrated Traditional Chinese and Western Medicine, Medical College of Yangzhou University, Yangzhou, 'Department of Gastrointestinal Surgery Taizhou people's Hospital, Taizhou, 'Department of Gastrointestinal Surgery, Clinical Medical College of Yangzhou University, Subei People's Hospital of Jiangsu Province, Yangzhou, China
\end{abstract}

\section{Key Words}

Galectin - Sphingosine-1-phosphate receptor 1 - Epithelial-mesenchymal transition - Gastric cancer $\cdot$ Metastasis

\begin{abstract}
Background/Aims: Increased expression of galectin-1 (Gal-1) in gastric cancer (GC) promotes metastasis and correlates with poor prognosis. The mechanisms by which Gal-1 promotes GC metastasis remain unknown. Methods: Gal-1and Sphingosine-1-phosphate receptor 1 (S1PR1) were determined by immunohistochemistry $(\mathrm{IHC})$ and quantitative real time polymerase chain reaction (qRT-PCR) in GC specimens. Stably transfected Gal-1 or S1PR1 into SGC7901 and MGC-803 cells, western blot and invasion assays in vitro and nude mice tumorigenicity in vivo were also employed. Results: Overexpression of Gal-1 enhanced expression of S1PR1 in SGC7901 cells, and increased cell invasion, while knockdown Gal-1 in MGC-803 cells reduced S1PR1 expression and diminished invasion. Simultaneous knockdown of Gal-1 and overexpression of S1PR1 in MGC803 cells rescued invasive ability of MGC803 cells. S1PR1 was associated with expression of epithelial-to-mesenchymal transition (EMT) markers in vitro and in clinical samples. EMT induced in MGC-803 cells by TGF- $\beta 1$ was accompanied by S1PR1 activation, while knockdown of S1PR1 reduced response to TGF- $\beta 1$, suggest that Gal-1 promotes GC invasion by activating EMT through a S1PR1-dependent mechanism. Overexpression of S1PR1 promoted subcutaneous xenograft growth and pulmonary metastases, and enhanced expression of EMT markers. Conclusion: Galectin-1 promotes metastasis in gastric cancer through a S1PR1- dependent mechanism, our results indicate that targeting S1PR1 may be a novel strategy to treat GC metastasis.




\section{Cellular Physiology Cell Physiol Biochem 2018:51:11-30 and Biochemistry \begin{tabular}{l|l} 
DOI: 10.1159/000495157 & $\begin{array}{l}\text { C } 2018 \text { The Author(s). Published by S. Karger AG, Basel } \\
\text { www.karger.com/cpb }\end{array}$
\end{tabular} You et al.: Galectin-1 Promotes GC Metastasis}

\section{Introduction}

Gastric cancer is one of the most common cancers, and is the third leading cause of cancer-related deaths worldwide $[1,2]$. Over the past two decades, the incidence of GC has increased globally $[3,4]$, especially in Japan China, and Korea $[5,6]$. The majority of patients with GC are diagnosed at advanced stages, with a high frequency of recurrence and metastasis [7]. Approximate $70 \%$ of patients with advanced GC present with tumor metastasis and suffer from recurrence within 5 years after resection, counting for a majority of cancerrelated deaths [8]. Metastatic progression, i.e. the spread of primary tumor to distant organs, is a complex, multistep pathological process with unclear mechanisms. An elucidation of underlying mechanisms of metastatic progression is critical for the identification of novel therapeutic targets and development of agents.

Galectin-1 (Gal-1) is one of 15 members of the $\beta$-galactoside binding family of proteins, called the galectin. Gal-1 is encoded by the LGALS1 gene, which is found as a homodimeric protein consisting of $14.5 \mathrm{kDa}$ subunits $[9,10]$. Gal-1 is synthesized on cytosolic ribosomes, and incorporated into the nucleus from the cytosol, and translocated to the intracellular side of cell membranes, or secreted [11]. In the intracellular environment, Gal-1 acts as a scaffold protein for intracellular signaling pathways in a carbohydrate independent manner, which participates in protein-protein interactions with H-Ras [12]. In the extracellular environment, Gal-1 mediates cellular aggregation, promotes tumor formation, and participates in defining $\beta$-galactoside activity $[11,13]$. Gal- 1 is altered in a variety of cancer cell types [14-17], including GC [18]. Gal-1 expression is found in GC, and aberrant Gal-1 expression enhanced GC cell migration and in vitro invasion $[19,20]$. In the clinical setting, increased Gal-1 expression was found to be associated with poor prognosis [18].

Sphingosine-1-phosphate receptor 1 (S1PR1), is encoded by the S1PR1 gene, also known as endothelial differentiation gene 1 (EDG1). S1PR1 is a G-protein-coupled receptor (GPCR) for lysophospholipid sphingosine-1-phosphate (S1P) [21, 22]. S1PR1 belongs to a sphingosine-1-phosphate receptor (S1PR) subfamily comprised of five members (S1PR1S1PR5)[21]. Like other GPCRs, S1PR1 is composed of seven transmembrane helices arranged in a structurally conserved bundle [21]. In the extracellular region, S1PR1 is composed of three loops, which sense extracellular ligand and activate intracellular signaling pathways, ultimately leading to cellular responses with various biologic effects, including cell proliferation, survival, and migration via the ERK, Akt, and Rac pathways [23]. It was reported that the signal transducer and activator of transcription 3 (STAT3) transcription factor regulated S1PR1 gene expression, and S1PR1 induced persistent STAT3 activation [24]. Additionally, S1PR1 expression was found to enhance GC cell migration and invasion in vitro and in vivo $[25,26]$. Overexpression of S1PR1/STAT3 was speculated to promote metastasis in GC, leading to a poor prognosis [26-28]. However, underlying mechanisms of S1PR1's promotion of metastasis in GC and the association between S1PR1 and Gal-1 are unclear. In this study, we explored the association between S1PR1 and Gal-1 expression, and mechanisms of interactions of these genes in promotion of GC metastasis.

\section{Materials and Methods}

\section{Patients and tissue samples}

Patients were recruited form Department of Gastrointestinal Surgery, Clinical Medical College of Yangzhou University (Taizhou people's Hospital of Jiangsu Province). After exclusion of patients without complete clinicopathological and follow-up data, 127 patients with GC were enrolled in our study from July 2012 to May 2013. Formalin-fixed tumor tissues were used for conventional histological hematoxylin-eosin (H\&E) staining and immunohistochemistry (IHC), while fresh tumor samples and matching adjacent nontumor tissues from 15 patients were used for molecular and biological analyses. 


\section{Cellular Physiology Cell Physiol Biochem 2018;51:11-30

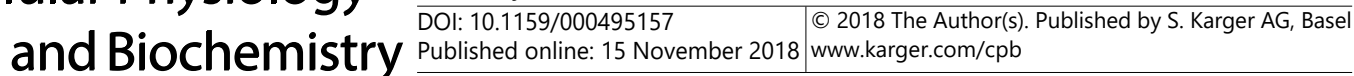 \\ You et al.: Galectin-1 Promotes GC Metastasis}

Detailed clinicopathological data of these patients are shown in Table 1. All patients underwent radical gastrectomy for the primary tumor and D2 lymphadenectomy. None of the patients received chemotherapy or radiotherapy, or had distant metastases prior to surgery. None of the patients had other synchronous malignancies or serious systemic diseases. This study was approved by the ethics committee of Taizhou People's Hospital.

\section{Reagents and antibodies}

The reagent TGF- $\beta 1$ was purchased from Peprotech (Rocky Hill, NJ, USA). Anti-galectin-1 antibody (Cell Signaling Technology, Danvers, MA, USA), anti-S1PR1 antibody (Abcam, Cambridge, UK), anti-E-Cadherin antibody (Cell Signaling Technology), anti-vimentin (Cell Signaling Technology), antiGAPDH antibody (Santa Cruz Biotechnology, Santa Cruz, CA, USA), horse radish peroxidase (HRP)conjugated goat anti-mouse IgG (Santa Cruz Biotechnology), and HRP-conjugated goat anti-rabbit IgG (Santa Cruz Biotechnology) were used in this study.

\section{Histological evaluation}

Immunohistochemical staining was performed on formalin-fixed, paraffin-embeded tissue specimens. Slides were cut at $4 \mu \mathrm{m}$ thickness. Paraffin sections were deparaffinized in xylene and rehydrated in a gradient of ethanol solutions. Endogenous peroxidases were blocked with $3 \%(\mathrm{~V} / \mathrm{V})$ hydrogen peroxide in methanol for $10 \mathrm{~min}$. Sections were washed with phosphate-buffered saline (PBS), and then pretreated with citrate buffer ( $\mathrm{pH} \mathrm{6.0)}$ ) for 20 minutes at $95^{\circ} \mathrm{C}$ in a microwave oven for antigen retrieval. Slides were then incubated with primary antibodies against Gal-1 (1:200), S1PR1 (5 $\mu \mathrm{g} / \mathrm{ml})$, E-cadherin (1:200), or vimentin $(1: 200)$ overnight at $4^{\circ} \mathrm{C}$, followed by incubation with biotin-conjugated secondary antibodies, then horseradish peroxidase-conjugated streptavidin. Sections were stained with diaminobenzidine (DAB) and counterstained with hematoxylin. Finally, sections were mounted and cover slipped. Negative controls were treated identically, though primary antibodies were omitted; and positive controls were provided by the kit supplier. All specimens were stained in three sections for each antibody. The results were assessed by two independent pathologists who had no knowledge of the patient clinical status. E-cadherin and vimentin staining was defined as positive or negative. Positive staining was moderate or strong staining: brown or dark brown staining in $>20 \%$ of tumor cells. To quantify the immunostaining of Gal-1 and S1PR1, slides were imaged digitally with equal light exposure and evaluated by Image Pro Plus (IPP), a digitalized IHC scoring program (Media Cybernetics, San Diego, CA). The immunostaining results were scored by the product of the percentage of immunopositive cells (0-100) multiplied by staining intensity score $(0,1,2$, and 3) to yield scores of $0-300$.
Table 1. Associations between Gal-1 and S1PR1 immunostaining cancer assessed using the chi-square test

\begin{tabular}{|c|c|c|c|c|c|c|c|}
\hline \multirow[t]{2}{*}{ Parameters } & \multirow[t]{2}{*}{$\mathrm{n}$} & \multicolumn{2}{|c|}{ Gal-1 } & \multirow[t]{2}{*}{ P value } & \multicolumn{2}{|c|}{ S1PR1 } & \multirow[t]{2}{*}{$P$ value } \\
\hline & & $(-)$ & $(+)$ & & $(-)$ & $(+)$ & \\
\hline Age (yr) & & & & 0.391 & & & 0.879 \\
\hline$\leq 60$ & 37 & 14 & 23 & & 7 & 30 & \\
\hline$>60$ & 90 & 27 & 63 & & 16 & 74 & \\
\hline Gender & & & & 0.599 & & & 0.344 \\
\hline Male & 89 & 30 & 59 & & 18 & 71 & \\
\hline Female & 38 & 11 & 27 & & 5 & 33 & \\
\hline Tumor size & & & & $<0.001$ & & & $<0.001$ \\
\hline$<2 \mathrm{~cm}$ & 16 & 15 & 1 & & 12 & 4 & \\
\hline $2-5 \mathrm{~cm}$ & 47 & 21 & 26 & & 9 & 38 & \\
\hline$>5 \mathrm{~cm}$ & 64 & 5 & 59 & & 2 & 62 & \\
\hline Tumor location & & & & 0.758 & & & 0.905 \\
\hline Upper third & 12 & 5 & 7 & & 2 & 10 & \\
\hline Middle third & 65 & 20 & 45 & & 11 & 54 & \\
\hline Lower third & 50 & 16 & 34 & & 10 & 40 & \\
\hline Differentiation & & & & $<0.001$ & & & $<0.001$ \\
\hline Well & 15 & 14 & 1 & & 14 & 1 & \\
\hline Moderate & 72 & 21 & 51 & & 8 & 64 & \\
\hline Poor & 40 & 6 & 34 & & 1 & 39 & \\
\hline Depth of tumor invasion & & & & 0.002 & & & $<0.001$ \\
\hline $\mathrm{T} 1$ & 15 & 10 & 5 & & 10 & 5 & \\
\hline $\mathrm{T} 2-\mathrm{T} 4$ & 112 & 31 & 81 & & 13 & 99 & \\
\hline TNM stage & & & & $<0.001$ & & & $<0.001$ \\
\hline 1 & 16 & 14 & 2 & & 11 & 5 & \\
\hline II & 39 & 20 & 19 & & 9 & 30 & \\
\hline III & 61 & 4 & 57 & & 1 & 60 & \\
\hline IV & 11 & 3 & 8 & & 2 & 9 & \\
\hline Lymph node status & & & & $<0.001$ & & & $<0.001$ \\
\hline Positive & 71 & 7 & 64 & & 4 & 67 & \\
\hline Negative & 56 & 34 & 22 & & 19 & 37 & \\
\hline Tumor emboli in the micro-vessels & & & & $<0.001$ & & & 0.016 \\
\hline Positive & 44 & 4 & 40 & & 3 & 41 & \\
\hline Negative & 83 & 37 & 46 & & 20 & 63 & \\
\hline
\end{tabular}




\section{Cellular Physiology Cell Physiol Biochem 2018;51:11-30

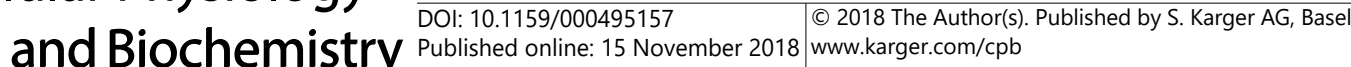

You et al.: Galectin-1 Promotes GC Metastasis

Cell culture

Human gastric adenocarcinoma cell lines AGS, SGC-7901, BGC-823, MGC-803, and HGC-27, were obtained from the Type Culture Collection of the Chinese Academy of Sciences (Shanghai, China). The cells were maintained with Roswell Park Memorial Institute medium (RPMI Hyclone, Logan, Utah, USA) supplemented with 10\% (V/V) FBS (Thermo Scientific HyClone, Logan, Utah, USA), 100 U/ml penicillin, and $100 \mathrm{mg} / \mathrm{ml}$ streptomycin (GIBCO, Grand Island, NY, USA). All cells were maintained at $37^{\circ} \mathrm{C}$ in a humidified atmosphere containing $5 \%(\mathrm{~V} / \mathrm{V}) \mathrm{CO}_{2}$. Cells were cultured to a confluence of $80 \%$ and passaged via trypsinization.

\section{Lentiviral transduction}

Lentiviral vectors carrying green fluorescent protein (GFP) and a puromycin resistance gene for Gal-1 overexpression and knockdown, or S1PR1 overexpression and knockdown, were commercially constructed by Genechem Co. Ltd (Shanghai, China). The negative control lentiviral vector also expressed green fluorescent protein and a puromycin resistance gene. MGC-803 or SGC-7901 cells were seeded on 6 -well plates at a concentration of $5 \times 10^{4}$ cells per well on the day before lentiviral transduction. Cells were transduced with the appropriate lentiviral vector containing at a multiplicity of infection (MOI) of 10 in the presence of $10 \mu \mathrm{g} / \mathrm{ml}$ polybrene (Sigma-Aldrich, St. Louis, MO, USA). Additionally, each cell line was transduced with a non-targeting negative control lentiviral vector by the same approach to control for effects of viral vector transduction. After incubation at $37^{\circ} \mathrm{C}$ for 12 hours, the medium was replaced with the appropriate fresh medium. After incubation for $48 \mathrm{~h}$, puromycin (Sigma-Aldrich) was added at concentration of $2 \mu \mathrm{g} / \mathrm{ml}$ to select for stably transduced cell lines. Stable transductants were cultured in the presence of puromycin at concentration of $0.5 \mu \mathrm{g} / \mathrm{mL}$. Transduction efficiencies were evaluated 72 hours after transduction by counting GFP positive cells under a fluorescent microscope (OLYMPUS-U-HGLGPSIX73); positive transduction was and further confirmed by qRT-PCR or western blot.

\section{RNA extraction and real-time PCR}

Real-time PCR was performed to determine the mRNA expression levels of Gal-1 and S1PR1.Total RNA was extracted using the RNeasy Mini Kit (Invitrogen, Carlsbad, CA, USA) according to manufacturer's instructions. First strand cDNA synthesis was performed with a reverse transcription kit (Takara, Carlsbad, CA, USA). Quantitative PCR was performed with SYBR Green dye (Roche Diagnostics, Mannheim, Germany). Relative levels of mRNA expression were analyzed using a Light Cycler 480 system (Roche Diagnostics). The PCR parameters were $30 \mathrm{~s}$ at $95^{\circ} \mathrm{C}$ followed by 40 cycles at $95^{\circ} \mathrm{C}$ for $5 \mathrm{~s}, 60^{\circ} \mathrm{C}$ for $30 \mathrm{~s}$, and $72^{\circ} \mathrm{C}$ for 30 s. The GAPDH gene was used as an internal control. Fold changes in the mRNA levels of target genes were calculated relative to GAPDH. All results are reported as the average ratios of three different independent experiments. The following primers were used: Gal-1 (forward): GCTGAACCTGGGCAAAGACAG and (reverse) GTTGAGGCGGTTGGGGAACTT (247bp); S1PR1 (forward) TTTCCTGGACAGTGCGTCTC and (reverse) ACTGACTGCGTAGTGCTCTC (250bp); and GAPDH (forward) TGACTTCAACAGCGACACCCA) and (reverse) CACCCTGTTGCTGTAGCCAAA (121bp).

\section{Western blot analysis}

Harvested cells were lysed in a buffer containing $40 \mathrm{mM}$ Tris-Cl, $10 \mathrm{mM}$ EDTA, $120 \mathrm{mM} \mathrm{NaCl}, 0.1 \%(\mathrm{~V} / \mathrm{V}$ ) Nonidet P-40, and a protease inhibitor cocktail (Sigma-Aldrich). Total protein (20 $\mu \mathrm{g}$ ) from each lysate were separated by SDS-PAGE and transferred to a nitrocellulose membrane (GE Healthcare Life Sciences, Pittsburgh, PA, USA), Blots were probed with anti-Gal-1, anti-S1PR1, anti-vimentin, and anti-E-cadherin, or anti-GAPDH (KangCheng, Shanghai, China) at a concentration of 1:2000. For subcellular localization of proteins, total cell extracts and nuclear extracts were prepared using an extraction kit (Beyotime, Shanghai, China). HRP conjugated immunoglobulin was used as a secondary antibody at a concentration of 1:2000. West Pico chemiluminescent Substrate (Pierce, Carsbad, CA, USA) was used to visualize protein bands, and densitometric image analysis software (Image Master VDS; Pharmacia Biotech) was used to quantify the visualized protein bands. 


\section{Cellular Physiology Cell Physiol Biochem 2018;51:11-30 and Biochemistry Publisned \begin{tabular}{l|l} 
DOI: 10.1159/000495157 & $\begin{array}{l}\text { (c) } 2018 \text { The Author(s). Published by S. Karger AG, Basel } \\
\text { www.karger.com/cpb }\end{array}$
\end{tabular} \\ You et al.: Galectin-1 Promotes GC Metastasis}

Cell invasion assay

The invasive ability of GC cells was measured using 24-well transwell units with polycarbonate filters (pore size, $8.0 \mu \mathrm{m}$; Corning, New York, USA). In brief, the upper Transwell inserts were coated with 100 $\mu \mathrm{l}$ Matrigel ${ }^{\circledR}$ basement membrane (BD Biosciences, San Diego, CA, USA) and serum-free RPMI medium mixture at a ratio of $1: 8$. Next, $1 \times 10^{5}$ cells in $100 \mu \mathrm{L}$ serum-free RPMI medium were seeded in the top chamber. For the chemoatractant, $600 \mu \mathrm{l}$ of medium containing 10\% (V/V) FBS was placed in the lower chambers. Cells were allowed to migrate for $24 \mathrm{~h}$ at $37^{\circ} \mathrm{C}$, after which non-invasive cells were removed with a cotton swab. The filters were fixed with $4 \%(\mathrm{~V} / \mathrm{V})$ paraformaldehyde, and cells were stained with a $0.05 \%$ $(\mathrm{V} / \mathrm{V})$ crystal violet solution, then counted under a microscope. Tumor cell invasion assays were performed in triplicate.

\section{Animal models}

Subcutaneous GC implantation and tail vein injected models were established in five-week-old male athymic BALB/c mice; the animal experiments were approved by the Ethic Committee of Yang Zhou University (Yang Zhou, Jiangsu, China). MGC-803 cells with S1PR1 overexpression (OE-S1PR1), S1PR1 knock-down (KD-S1PR1), or empty vector (NC) cells were separately inoculated into the right sides of the back or injected into the tail vein $\left(2 \times 10^{6}\right.$ cells/mouse; $n=6$ /group). Diameters of the subcutaneous tumors were measured every three days. Mice were sacrificed on day 21 or 35, subcutaneous GC tumors and lung metastases were harvested, and histological examination was performed after H\&E or immunostaining.

\section{Statistical analysis}

Statistical analysis was conducted with SPSS 16.0 software (SPSS Inc., Chicago, IL, USA). Continuous variables were expressed as the means $\pm \mathrm{SE}$ and were compared between groups by using the Student's t-test. The Chi-square test was applied for comparison of dichotomous variables. Correlations were assessed by the nonparametric Spearman-Rho method. The Kaplan-Meier method was used for survival analysis, and differences of survival between groups were assessed with the log-rank test. In all analyses, $P<0.05$ was considered statistically significant.

\section{Results}

\section{Gal-1 and S1PR1 are over-expressed in GC tissues}

In order to understand the expression of Gal-1 and S1PR1 in GC, we performed IHC analyses of 127 GC specimens and matched non-tumor tissues from patients with GC. All tissue slides were digitally imaged and evaluated by Image Pro Plus (IPP, Media cybernetics, San Diego, CA), to avoid subjective bias. GC tissues exhibited significantly higher expression of Gal-1 and S1PR1 (Fig. 1A) than matched non-tumor tissue specimens, while the latter exhibited only slight to moderate expression (Fig. 1B). In GC tissues, the median IHC scores of Gal-1 and S1PR1 were 78.29 (9.51-186.24) and 43.97 (3.16-103.56), respectively. In comparison, the IHC scores of Gal-1 and S1PR1 in non-tumor tissues were 31.09 (5.89123.45) and 17.45 (2.34-78.76), respectively. We observed a significant difference in Gal-1 and S1PR1 expression between GC and non-tumor tissues ( $P<0.01$; Fig. 1C). Gal-1 expression was positively correlated with S1PR1 expression in GC tissues ( $\mathrm{r}=0.870, P<0.01$; Fig. 1D).

To confirm the results of Gal-1 and S1PR1 in GC and matched non-cancer tissues, we performed quantitative real-time PCR (qRT-PCR) to evaluate Gal-1 and S1PR1 mRNA expression in 15 matched tumor and non-tumor tissues. The results of qRT-PCR were consistent with the IHC results, demonstrating overexpression of Gal-1 and S1PR1 in GC tissues (Fig. 1E).

Over-expression of Gal-1 and S1PR1 is positively associated with lymph node metastasis

Positive lymph node metastases were identified in 71 of 127 patients (55.9\%) with GC by hematoxylin-eosin staining (Fig. 2A). As tumor-node metastasis staging is one of the most important factors for biological behavior of tumor, we evaluated the expression of Gal-1 and S1PR1 in metastatic lymph nodes by immunostaining (Fig. 2B). An enhanced expression of 


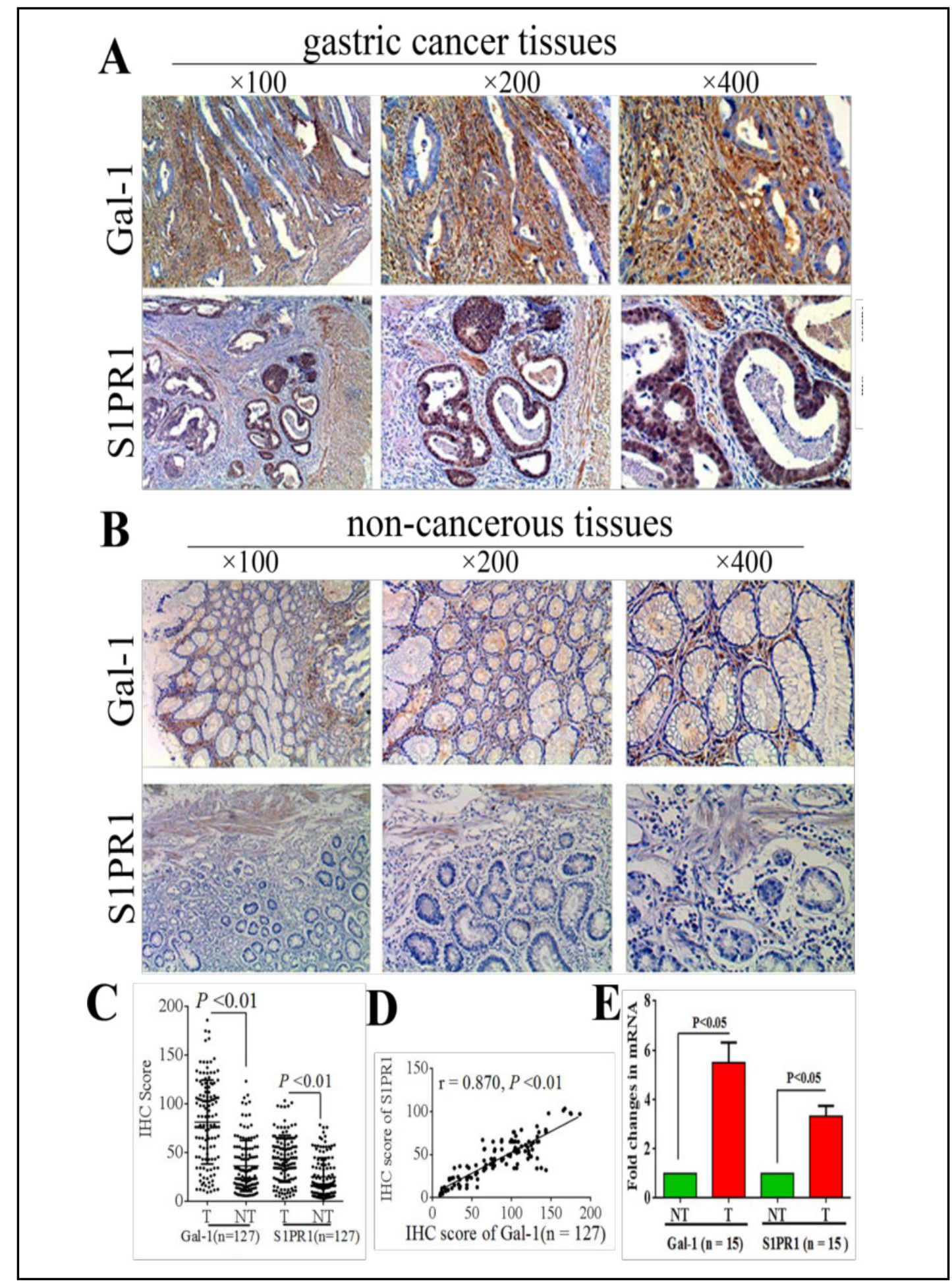

Fig. 1. Gal-1 and S1PR1 are over expressed in GC tissues. Representative images of IHC for Gal-1 and S1PR1 in a human gastric cancer tissue and b matched non-cancer tissues. c. IHC scores for Gal-1 and S1PR1 were compared between tumor and matched non-tumor tissues. d. Gal-1 expression was positively correlated with S1PR1 expression in gastric cancer tissues. e. Expression of Gal-1 and S1PR1 mRNA in 15 gastric cancer and matched non-cancerous tissues, expression was shown as fold changing. T: tumor tissue, NT: non-tumor tissue.

\section{KARGER}




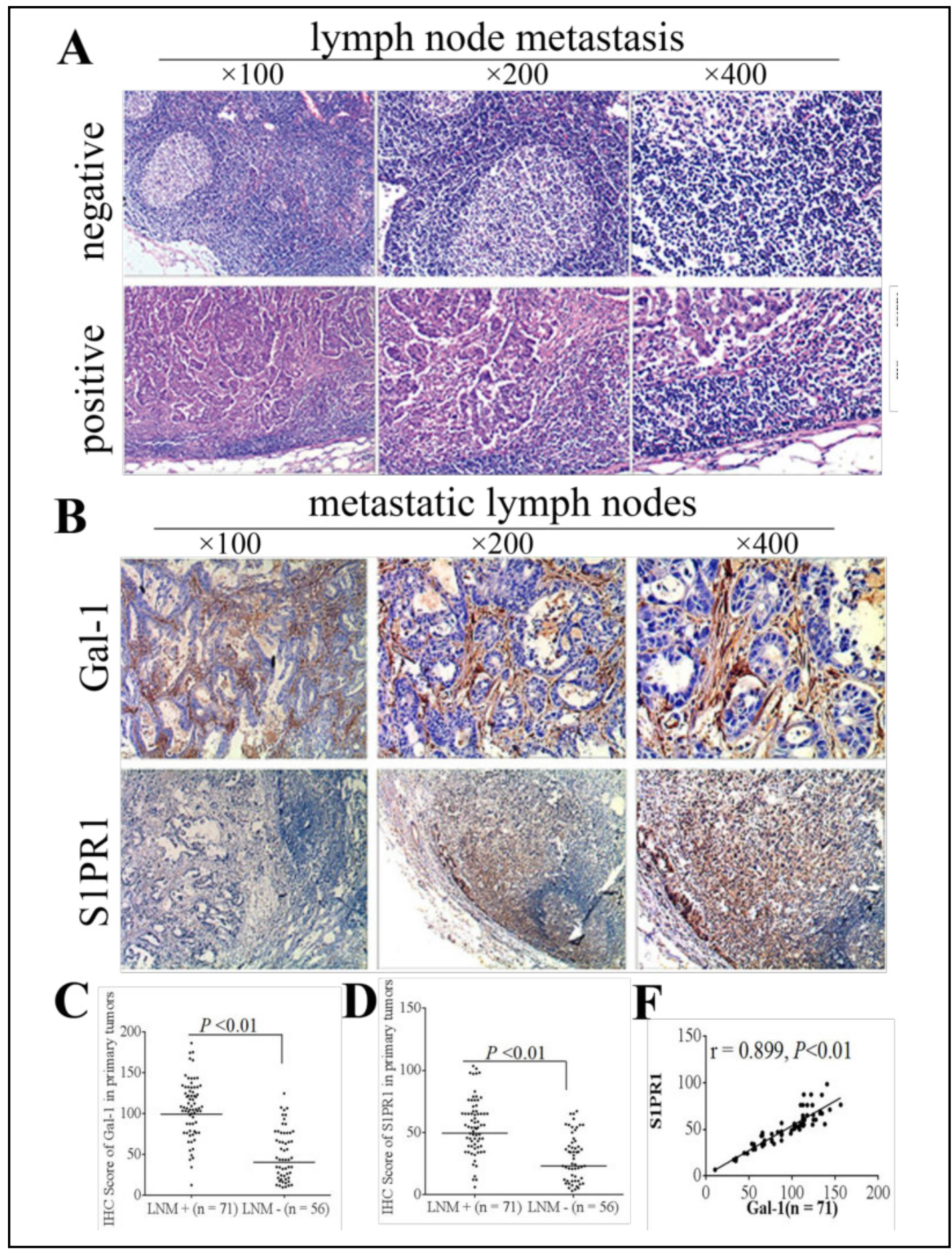

Fig. 2. Over expression of Gal-1 and S1PR1 are positively associated with lymph node metastasis. a. Positive and negative lymphatic metastasis by H\&E staining. b. IHC analysis of Gal-1 and S1PR1 expression in gastric cancer metastatic lymph node tissues. IHC score of c Gal-1 and d S1PR1 in matched primary tumors with lymph node metastases compared to primary tumors without lymph node metastases. e. Gal-1 expression was positively correlated with S1PR1 expression in gastric cancer metastatic lymph nodes. LNM+: positive for lymph node metastasis, LNM-: negative for lymph node metastasis. 
Gal-1 and S1PR1 in primary tumors and matched metastatic lymph nodes was observed, in contrast to Gal-1 and S1PR1 expression in primary tumors without lymph node metastasis (Fig. 2C, D; $P<0.01$ ).

We quantified the IHC score in Gal-1 and S1PR1 of metastatic lymph nodes, and analyzed the association between Gal-1 and S1PR1 expressions in metastatic lymph nodes. We found that Gal-1 expression was positively correlated with S1PR1 expression in metastatic lymph node in GC ( $\mathrm{r}=0.899, P<0.01$; Fig. 1E). The results suggest that over-expression of Gal-1 and S1PR1 was positively correlated with the status of lymph node metastasis; and that Gal1 expression was positively correlated with S1PR1 expression in lymph node metastases in GC.

Aberrant Gal-1 and S1PR1 expression in primary tumors indicates poor prognosis in patients with $G C$

Receiver operating curve (ROC) statistics was employed to estimate cut-off points for IHC scores to distinguish positive and negative expression of Gal-1 and S1PR1 in 127 GC samples. The IHC scores of Gal-1 $\geq 56.80$ and IHC scores of S1PR1 $\geq 21.05$ were considered as positive expression (Fig. 3A, B).

The median follow-up duration after surgery for the cohort was 39.6 months (range: $3.1-$ 60.9 months). A total of 75 cases (59.06\%) experienced disease metastasis or recurrence, and $68(53.54 \%)$ had tumor-related deaths. The median time to recurrence was 26.40 months (range: 1.0-59.8 months). Kaplan-Meier analysis revealed that the overall survival (OS) time was $52.56 \pm 2.44$ months (95\% confidence interval (CI): 47.77-57.35) for patients with Gal-

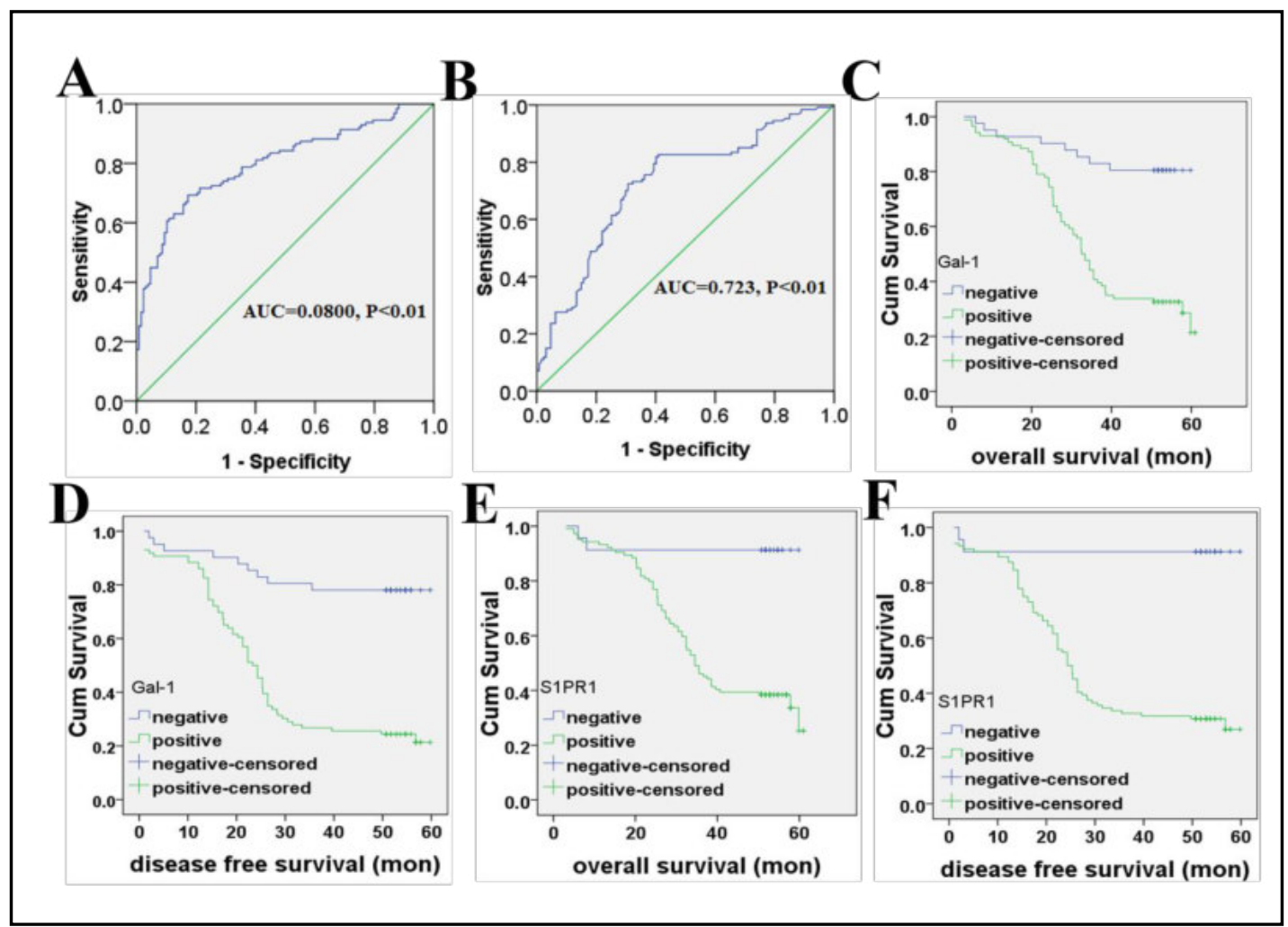

Fig. 3. Aberrant Gal-1 and S1PR1 expression in primary tumors indicates poor prognosis in patients with gastric cancer. ROC statistics were employed to estimate the cut-points of the IHC score for a Gal-1 and b S1PR1 in human gastric cancer tissue. Kaplan-Meier survival curves show that high Gal-1 expression in human gastric cancer tissues is associated with c poor overall survival and d poor disease free survival. High S1PR1 expression in human gastric cancer tissues is associated with e poor overall survival and f poor disease free survival. 


\section{Cellular Physiology Cell Physiol Biochem 2018;51:11-30

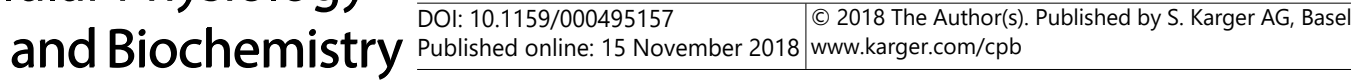 \\ You et al.: Galectin-1 Promotes GC Metastasis}

1 negative primary GC tissue and $37.17 \pm 1.95$ months (95\% CI: 33.36-40.99) for patients with Gal-1 positive primary GC tissue $\left(\chi^{2}=22.32, P<0.01\right.$; Fig. $\left.3 \mathrm{C}\right)$. The DFS time was 50.43 \pm 2.87 months (95\% CI: $44.80-56.06$ ) for patients with Gal-1 negative primary GC tissue and $28.81 \pm 2.08$ months (95\% CI: 24.73-32.89) for patients with Gal-1 positive primary GC tissue $\left(\chi^{2}=28.05, P<0.01\right.$; Fig. 3D). The OS time was $55.21 \pm 3.10$ months $(95 \% \mathrm{CI}$ : 49.14-61.29) for patients with S1PR1 negative primary GC tissue and $39.30 \pm 1.81$ months (95\% CI: 35.77-42.83) for patients with S1PR1 positive primary GC tissue $\left(\chi^{2}=15.97, P<\right.$ 0.01; Fig. 3E). The disease free survival (DFS) time was $54.82 \pm 3.37$ months (95\% CI: 48.2261.42) for patients with S1PR1 negative primary GC tissue and $31.54 \pm 1.98$ months $(95 \%$ CI: 27.66-35.43) for patients with S1PR1 positive primary GC tissue $\left(\chi^{2}=20.17, P<0.01\right.$; Fig. $3 F$ ). These findings indicate that both increased Gal-1 and increased S1PR1 in primary GC tumors can be considered as risk factors for poor prognosis in GC.

Gal-1 and S1PR1 expression is associated with invasiveness of GC cells

To confirm that Gal-1 and S1PR1 promote GC metastasis, we examined Gal-1 and S1PR1 protein expression in GC cell lines (including AGS, SGC-7901, BGC-823, MGC-803, and HGC-27 cells) by Western blot (Fig. 4A). The highly metastatic MGC-803 cell line showed the highest level of Gal-1 and S1PR1 protein expression, while the less metastatic SGC-7901 cell line demonstrated the lowest expression of Gal-1 and S1PR1 (Fig. 4A). We evaluated Gal-1 and S1PR1 mRNA expression in these five GC cell lines by PCR; and mRNA expression analysis confirmed Western blot results (Fig. 4B, C). To validate the ability of Gal-1 to promote GC cell invasion, we used lentiviral agents to over-express or knockdown Gal-1 in SGC-7901 or MGC-803 cells. Successful overexpression and knockdown of Gal-1 were confirmed by evaluation of the GFP signal and by Western blot (Fig. 4D-F). Gal-1 over-expression in SGC7901 cells increased S1PR1 expression and increased invasiveness (Fig. 4F, G), while Gal-1 knockdown in MGC-803 cells reduced S1PR1 expression and prevented invasion (Fig. 4E, $\mathrm{H})$. These results indicate that Gal-1 and S1PR1 expression may correlate with metastatic potential of GC cells.

Gal-1 promotes GC invasion through a mechanism dependent on enhanced expression of S1PR1

To further elucidate the relationship between expression of Gal-1 and S1PR1, MGC-803 cells were transfected with LV-S1PR1-RNAi (KD-S1PR1) to knockdown S1PR1, and SGC7901 cells were transfected with LV-S1PR1-OE (OE-S1PR1) to overexpress S1PR1. Successful overexpression and knockdown of S1PR1 were confirmed by analysis of GFP signal and by RT-PCR (Fig. 5A-C). Transfection of MGC-803 cells with LV-S1PR1-RNAi (KD-S1PR1) efficiently reduced S1PR1 expression and significantly reduced cell invasion as compared with untransfected (MGC-803) or negative control transfected (NC) MGC-803 cells (Fig. 5D, G). However, the expression of Gal-1 was unchanged (Fig. 5D). Similarly, transfection of SGC7901 cells with LV-S1PR1-OE (OE-S1PR1) efficiently induced S1PR1 protein expression and significantly promoted cell invasion as compared with untransfected (SGC-7901) or negative control transfected (NC) SGC-7901 cells (Fig. 5E, H), but did not change the expression of Gal-1 (Fig. 5E). Simultaneous knockdown of Gal-1 and over-expression of S1PR1 in MGC803 cells (KD-Gal-1+OE-S1PR1) restored invasive ability to the level of untransfected MGC803 cells (Fig. 5F, I). These findings suggested that Gal-1 promoted invasion in GC through a mechanism dependent on the enhanced expression of S1PR1. 


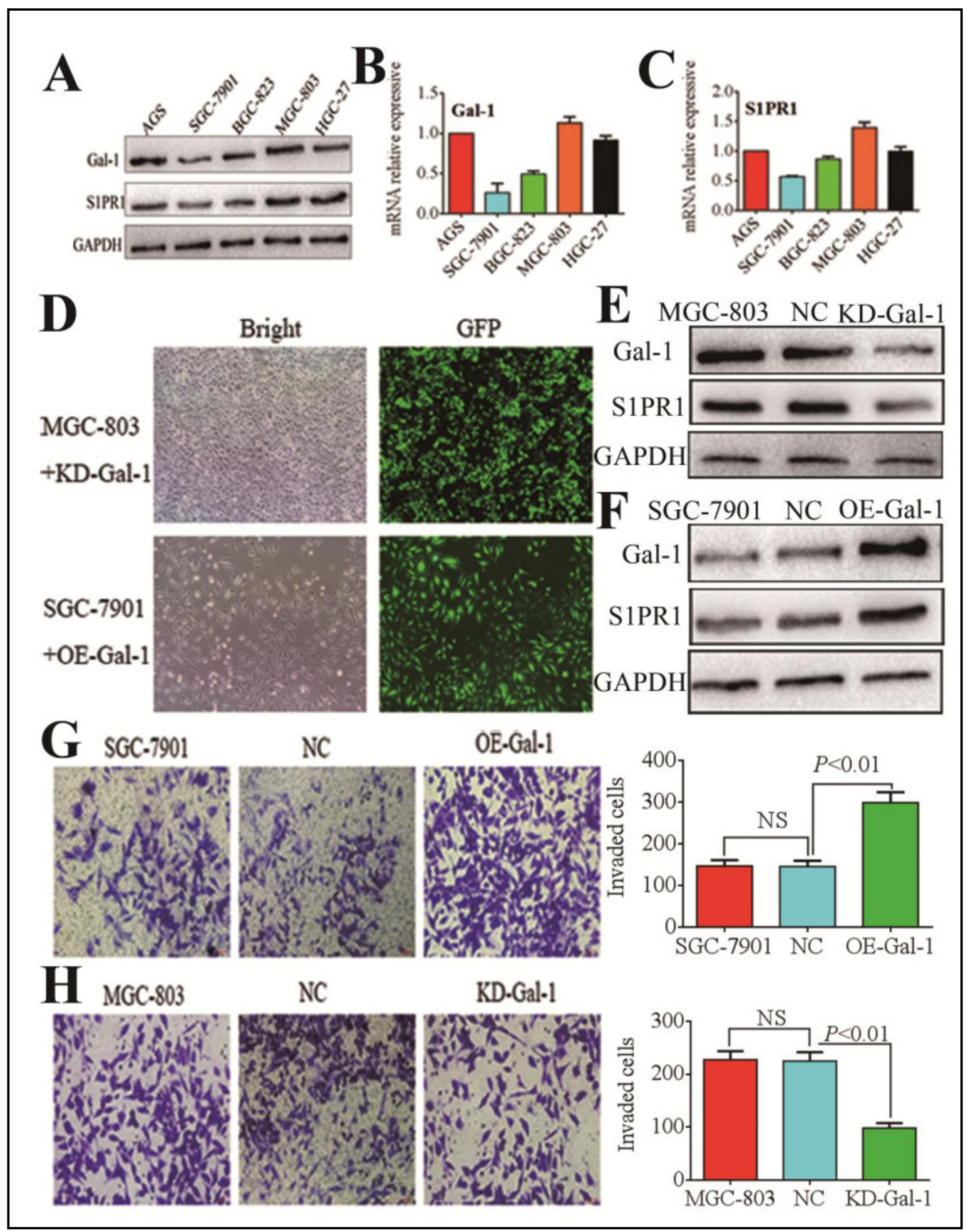

Fig. 4. Gal-1 and S1PR1 associates with invasiveness of gastric cancer cells. Western blot analysis of a Gal-1 and S1PR1 protein expression and RT-PCR analysis of $b$ Gal-1 and c S1PR1 gene expression in AGS, SGC7901, BGC-823, MGC-803, and HGC-27 gastric cancer cell lines. d. Transduction efficiency confirmed by GFP. Original magnification was 100×. e. Western blot confirmation of stable knockdown of Gal-1 and decreased expression of S1PR1 in MGC-803 cell line when Gal-1 is knocked down. f. Stable overexpression of Gal-1 increases expression of S1PR1 in SGC-7901 cells. Invasiveness of SGC-7901 was enhanced when g Gal-1 was over-expressed and h invasiveness of MGC-803 was weakened when Gal-1 was knocked down. The number of invaded cells was quantified by counting in six randomly-selected fields at $\times 200$ magnification. OE-Gal1:over-expression of Gal-1; NC: negative control (empty vector), KD-Gal: knockdown of Gal-1 expression. NS: not significant. 
A
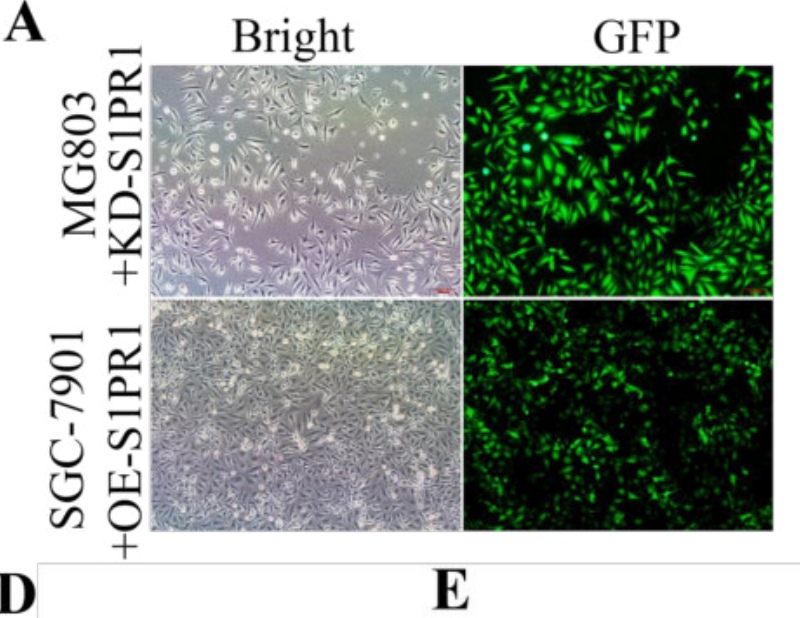

B

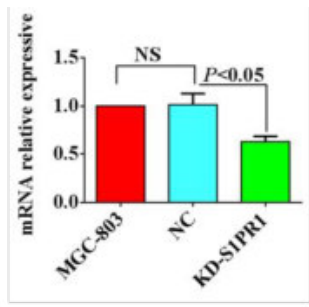

$\mathrm{C}$

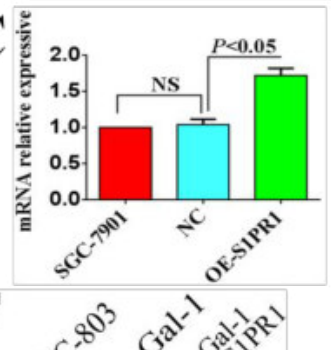

MGC-803 NC KD-S1PR1 SGC-790 NC OE-S1PR1
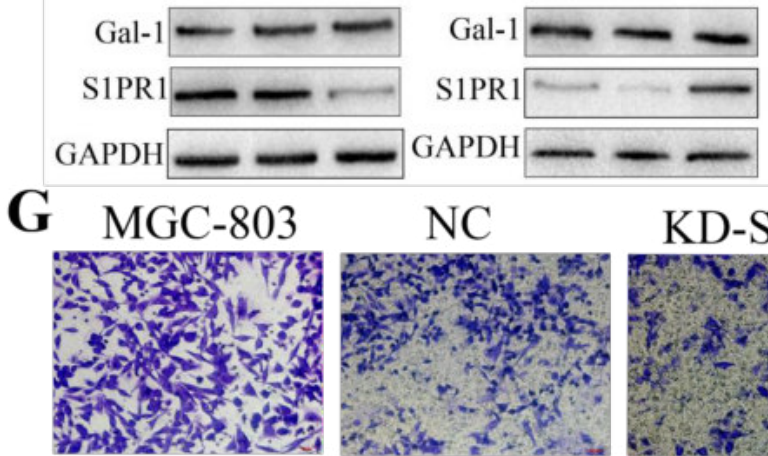

$\mathrm{NC}$

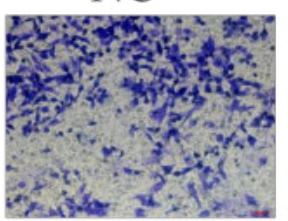

KD-S1PR1

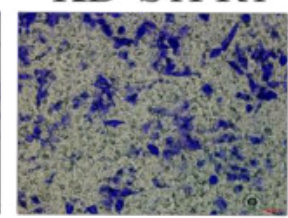

As

H SGC-7901

$\mathrm{NC}$
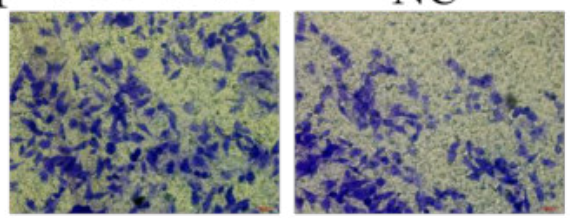

OE-S1PR1
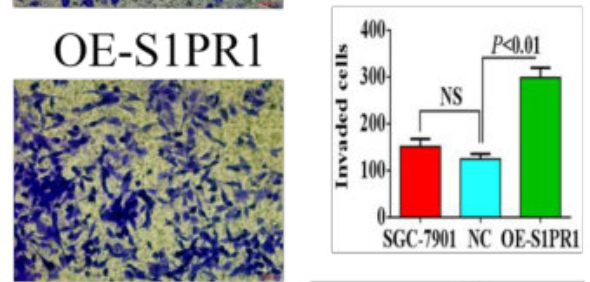

I MGC-803

KD-Gal-1

KD-Gal-1
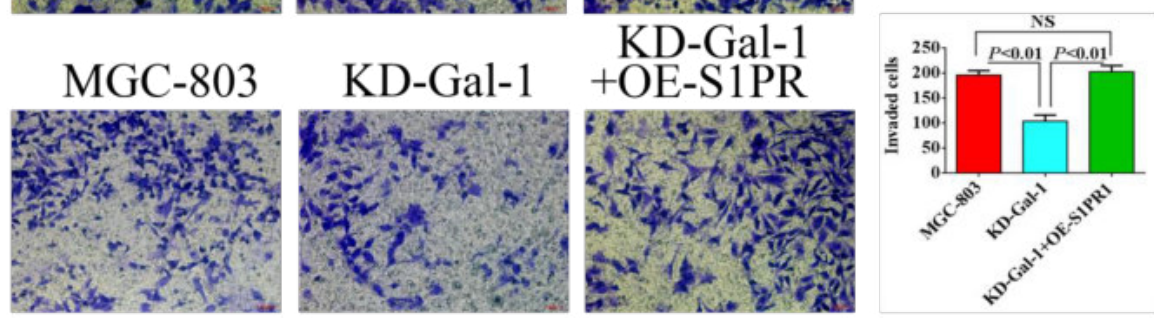

Fig. 5. Gal-1 promotes invasion in gastric cancer through a mechanism dependent on enhanced expression of S1PR1. Lentiviral transduction efficiency was confirmed by a GFP fluorescence and RT-PCR analysis for GFP in b MGC-803 cells and c SGC-7901 cells. Original magnification was 100x. S1PR1 knockdown or over-expression was confirmed with western blot in d MGC-803 cells and e SGC-7091 cells. f. Simultaneous knockdown of Gal-1 and over-expression of S1PR1 in MGC803 cells confirmed by western blot. Invasiveness of g MGC-803 cells was reduced with S1PR1 knockdown, while invasiveness of h SGC-7901 cells was enhanced with over-expression of S1PR1. i. Simultaneous knockdown of Gal-1 and over-expression of S1PR1 in MGC-803 cells rescued reduction in invasiveness from Gal-1 knockdown; magnification: $\times 200$. 


\section{$\begin{array}{lll}\text { Cellular Physiology } & \text { Cell Physiol Biochem 2018;51:11-30 } \\ \text { DOl: 10.1159/000495157 } & \text { O 2018 The Author(s). Published by S. Karger AG, Basel }\end{array}$

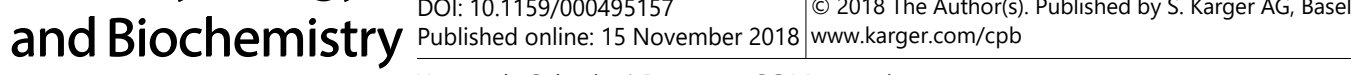

You et al.: Galectin-1 Promotes GC Metastasis

S1PR1 expression is elevated in a TGF- $\beta 1$ induced EMT model

The phenomenon known as epithelial-mesenchymal transition (EMT) promotes invasion and metastasis in many cancers [29-31], and we hypothesized that S1PR1 might be involved in EMT of GC cells. We treated MGC-803 cells with $10 \mathrm{ng} / \mathrm{ml}$ TGF- $\beta 1$ for 24 hours. Cells treated with TGF- $\beta 1$ (+TGF- $\beta 1$ ) exhibited a spindle-like and more elongated architecture than MGC-803 controls (Fig. 6A). The treatment of MGC-803 cells with TGF- $\beta 1$ significantly reduced protein expression of the epithelial marker and increased expression of mesenchymal marker vimentin (Fig. 6B). Meanwhile, the invasive ability of MGC-803 cells treated with TGF- $\beta 1$ (+TGF- $\beta 1$ ) was higher than that in MGC-803 controls (Fig. 6C). S1PR1 expression was significantly increased in TGF- $\beta 1$ treated cells (Fig. 6B), suggesting a possible role for S1PR1 in the EMT and invasion of GC cells.

\section{S1PR1 promotes invasion in GC through EMT}

The finding that S1PR1 was increased in MGC-803 cells after treatment with TGF- $\beta 1$ prompted us to determine whether overexpression of S1PR1 promotes the invasiveness of GC cells via inducing EMT. The overexpression of S1PR1 (OE-S1PR1) in MGC-803 cells induced a similar morphological transition treatment with TGF- $\beta 1$, as indicated by a decreased expression in E-cadherin and an increased expression in vimentin (Fig. 7A, B). On the other hand, MGC-803 cells with S1PR1 knockdown (KD-S1PR1) exhibited a significantly increased expression of E-cadherin and a decreased expression of vimentin (Fig. 7C). Furthermore, we assessed the responsiveness of control MGC-803 cells or S1PR1 knockdown MG803 cells (KD-S1PR1) to EMT by stimulating them with TGF- $\beta 1$ and evaluating the expression of E-cadherin and vimentin. After stimulation with TGF- $\beta 1$ for 24 hours, the invasiveness of MGC-803 cells was significantly increased, while the invasiveness of KD-S1PR1 cells was not (Fig. 7D). Treatment of MGC-803 with $10 \mathrm{ng} / \mathrm{ml}$ TGF- $\beta 1$ for 24 hours resulted in an increased

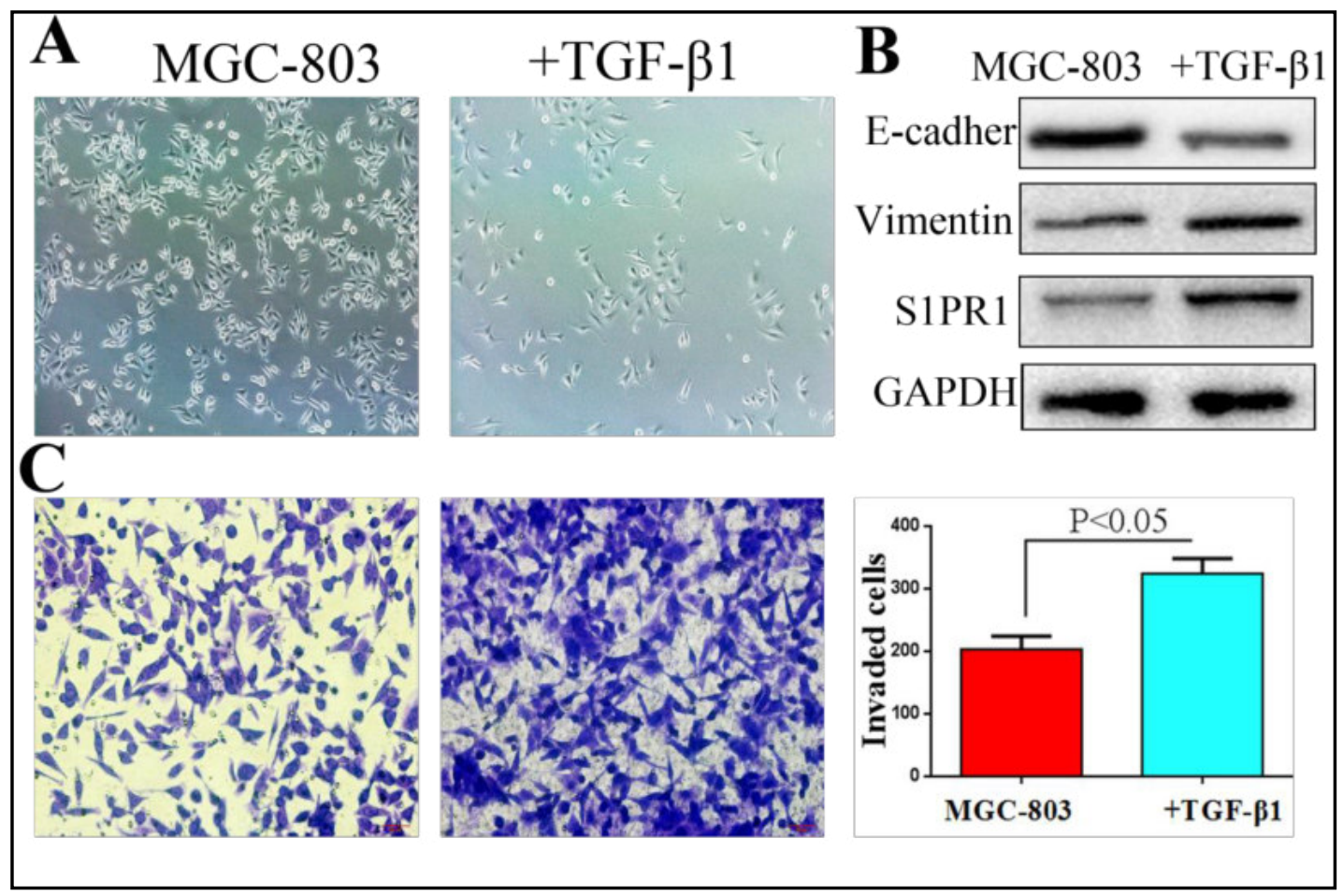

Fig. 6. S1PR1 expression is elevated in a model of TGF- $\beta 1$ induced EMT. MGC-803 cells were treated with TGF- $\beta 1$ at concentration of $10 \mathrm{ng} / \mathrm{ml}$ for 24 hours to induce EMT. a. Morphological changes of MGC-803 cells; Magnification: $\times 100$. b. Western blot showed increased vimentin expression and decreased E-cadherin expression, as well as increase in S1PR1 following TGF- $\beta 1$ treatment. c. Stimulation with TGF- $\beta 1$ increases invasiveness of MGC-803 cells, Magnification: $\times 200$. 


\section{Cellular Physiology Cell Physiol Biochem 2018;51:11-30

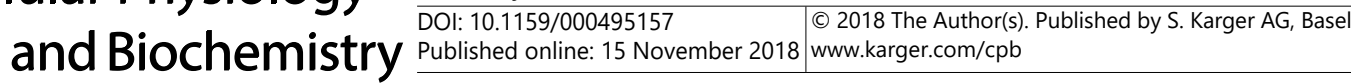 \\ You et al.: Galectin-1 Promotes GC Metastasis}

expression in vimentin protein and a decreased expression in E-cadherin (Fig. 6B). However, KD-S1PR1 cells lost EMT responsiveness as a result from TGF- $\beta 1$ stimulation (Fig. 7E). These results suggest that S1PR1 promotes invasion in GC through an EMT-associated mechanism.

\section{S1PR1 associates with EMT-related biomarkers in GC tissue}

To further confirm the correlation between S1PR1 and EMT, we examined E-Cadherin and vimentin in GC tissue with IHC. We identified positive vimentin staining in both tumor stroma cell and GC cells in 42 cases (Fig. 8A). Accordingly, the expression of E-cadherin was decreased in those samples that were vimentin positive (Fig. 8B). Moreover, in the 42 vimentin positive cases, the IHC score of S1PR1 in primary tumors were higher than in that in 85 vimentin negative cases (Fig. 8C). Furthermore, 30 of the 42 vimentin positive cases also had lymph node metastases, while only 41 of the 85 vimentin negative cases had lymph node metastases $(P<0.05$; Fig. 8D). These results suggest that EMT may be associated with GC metastasis, and S1PR1 may contribute to the metastatic process.

\section{Manipulation of S1PR1 expression influences GC xenograft growth and metastasis}

In clinical analysis and in vitro experiments, we demonstrated that Gal-1 promoted invasion in GC through an enhanced expression in S1PR1, and that S1PR1 contributed to GC metastasis through an EMT-mediated process. To further investigate the role of S1PR1 in GC invasion and metastasis, we generated subcutaneous GC implantation and lung metastasis models in athymic BALB/c mice ( $n=6 /$ group). Subcutaneous tumor xenografts

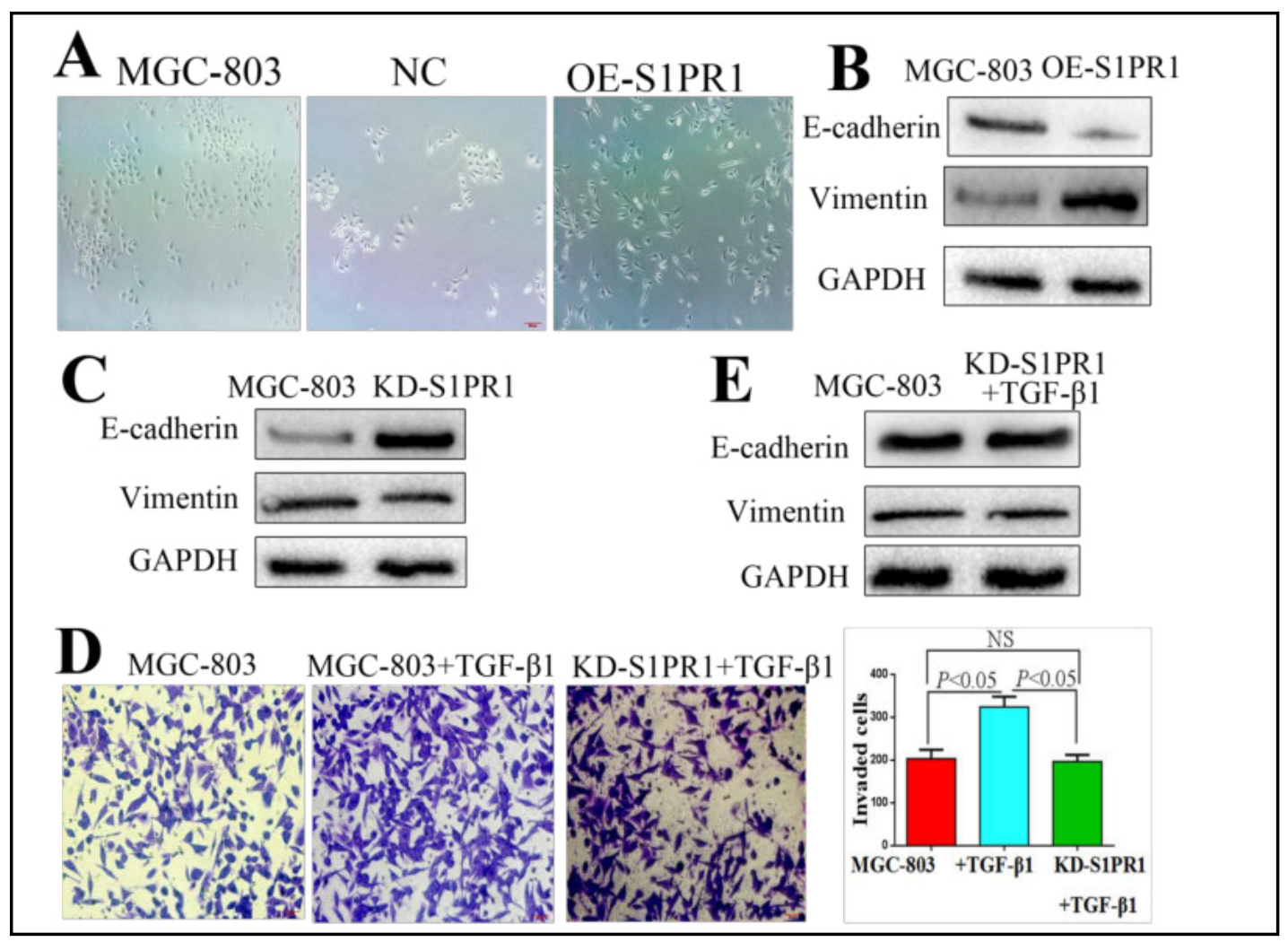

Fig. 7. S1PR1 promotes invasion in gastric cancer through EMT. a. Morphological changes of MGC-803 cells with over-expression of S1PR1. Western blot shows b increased vimentin expression and decreased E-cadherin expression in MGC-803 cells with over-expression of S1PR1, and c increased E-cadherin expression and decreased vimentin expression with knockdown of S1PR1. d. Stimulation of TGF- $\beta 1$ increases invasiveness of MGC-803 cells, while this effect was not observed when S1PR1 was knocked down. e. In MGC-803 cells with knockdown of S1PR1, expression of E-cadherin and vimentin were not changed upon treatment with TGF- $\beta 1$. 


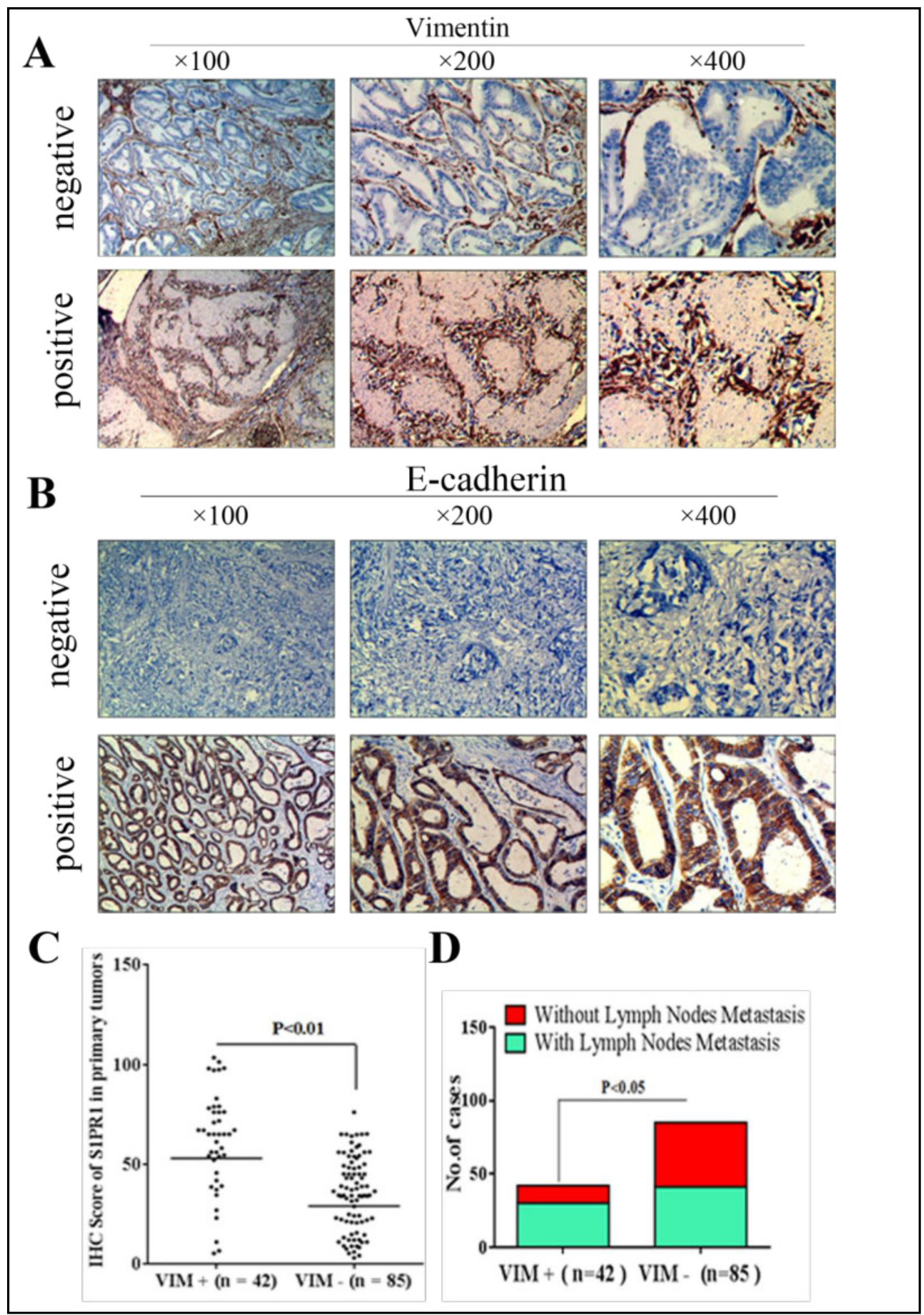

Fig. 8. S1PR1 associates with EMT related biomarkers in gastric cancer tissues. Negative and positive staining for a vimentin and b E-cadherin in gastric cancer cells. c. IHC score of S1PR1 in the matched primary tumors was compared between vimentin positive tumors and vimentin negative tumors. d. Lymph node metastases status was compared between vimentin positive GC cases and vimentin negative cases. VIM+: vimentin positive tumor, VIM-: vimentin negative tumor. 
were generated, including mice injected with either MGC-803 with S1PR1 over-expression (OE-S1PR1), S1PR1 knock-down (KD-S1PR1), or empty vector (NC). In addition, we injected these three MGC-803 transductants into the tail vein ( $n=6$ /group). The diameter of the implanted tumors was measured every three days. Twenty-one days after subcutaneous implantation, tumors in the OE-S1PR1 group were larger and heavier than that in the NCS1PR1 group, while KD-S1PR1 tumors were significantly smaller and lighter than that in the NC-S1PR1 group (Fig. 9A, B; $P<0.01$ ). Immunostaining showed that S1PR1 expression was increased in tumor tissue from the OE-S1PR1 group as compared with the NC-S1PR1 group, while the KD-S1PR1 group was negative for S1PR1 expression (Fig. 9A). Tumor volume was significantly higher in the OE-S1PR1 group than that in the control group (NC) from the day 6 onward, and significantly lower in the KD-S1PR1 group after day 9 (all $P<0.05$; Fig. 9C). Thirty-five days after tail vein injection, more pulmonary metastases were found in the OES1PR1 group than that in the NC group. Strikingly, the KD-S1PR1 group did not have any pulmonary metastases $(P=0.012$; Fig. 9D). Immunostaining showed pulmonary metastases in the OE-S1PR1 group compared with the NC group (Fig. 9E). We further examined EMT markers in the subcutaneous xenograft and pulmonary metastases with IHC. Both tumor and pulmonary metastases in the OE-S1PR1 group were positive for vimentin and negative for E-cadherin negative staining, while xenografts in the KD-S1PR1 group were vimentin negative and E-cadherin positive (Fig. 10). These results suggest that S1PR1 plays a role in $\mathrm{GC}$ invasion and metastasis, and indicate that EMT potentially contributes to the process.

\section{Discussion}

Development of better surgical techniques and new cytotoxic agents has improved prognosis for GC. However, the majority of patients with GC develop tumor metastasis and postoperative recurrence, leading to cancer related deaths despite therapy. Reasons for this likely may involve the large number of genetic alterations in GC, which may cause the GC tumors to acquire the ability to metastasize or to be resistant to chemotherapy [32]. Many cancer-related molecules have been characterized as targets of anticancer drug or as diagnostic markers forclinical decision-making in therapy and prognosis [33]. Previous reports have demonstrated that Gal-1 and S1PR1 promote gastric tumorigenesis and angiogenesis [18-20, 26, 28]. Our present study clarifies the role of Gal-1 and S1PR1 in GC, and explores the underlying mechanisms of metastasis.

In the present study, we observed that in tumor tissue samples from 127 patients with GC samples, Gal-1 is overexpressed in human GC as compared with matched nontumor tissues, which consistent with previous reports $[18,34]$. We also confirmed that expression of S1PR1 in human GC tissue was higher than in matched non-tumor tissue, and that expression of Gal-1 was positively correlated with S1PR1 expression in GC tissue. Moreover, the increased expression in Gal-1 and S1PR1 was significantly associated with tumor size, tumor differentiation, depth of tumor invasion, TNM stage, lymph node status, and the presence of tumor emboli in micro-vessels, suggesting that Gal-1 and S1PR1 may participate in tumor growth and metastasis. We compared the IHC score of Gal-1 and S1PR1 in primary GC tumors with lymph node metastases to primary GC tumors without lymph node metastasis. We also evaluated IHC scores of Gal-1 and S1PR1 in metastatic lymph nodes and analyzed the relationship between Gal-1 and S1PR1 in metastatic lymph nodes. We found that overexpression in Gal-1 and S1PR1 was positively associated with the status of lymph node metastasis. There is also a significant prognostic value of Gal-1 and S1PR1 expression in GC, as clinical outcomes for patients with Gal-1 or S1PR1 positive tumors were significantly poorer than that for patients with Gal-1 or S1PR1 negative tumors. Thus, evaluating Gal-1 and S1PR1 expression in GC tissues might be helpful for predicting disease prognosis. 


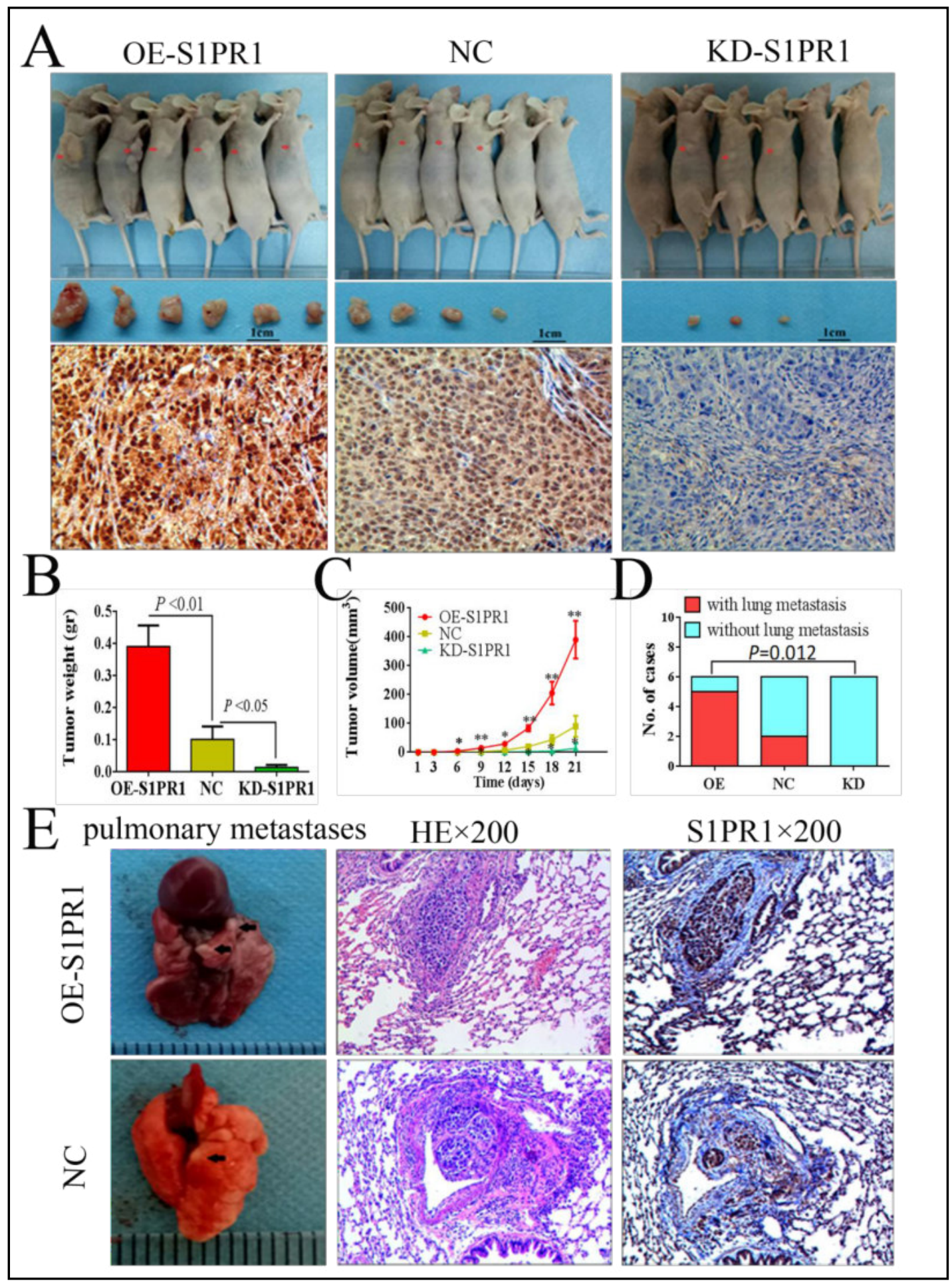

Fig. 9. Manipulation of S1PR1 expression influences gastric cancer xenograft growth and metastasis. a. S1PR1 overexpression induced MGC-803 to form bigger subcutaneous xenograft (red arrows); representative S1PR1-IHC; Magnification: $\times 400$. Tumor weight $b$ and volume cis expressed as the mean $\pm \mathrm{SE}$. $* \mathrm{P}<0.05$, ${ }^{* *}$ $\mathrm{P}<0.01, \mathrm{n}=6$. e. Representative images of metastasis (black arrows) in the lungs at 35 days after inoculation. Metastases were frequent in the d OE-S1PR1 group but were seldom detected in the NC group; the KDS1PR1 group did not develop pulmonary metastases; representative images of HE and IHC for S1PR1 in pulmonary metastases, Magnification: $\times 200$.

\section{KARGER}




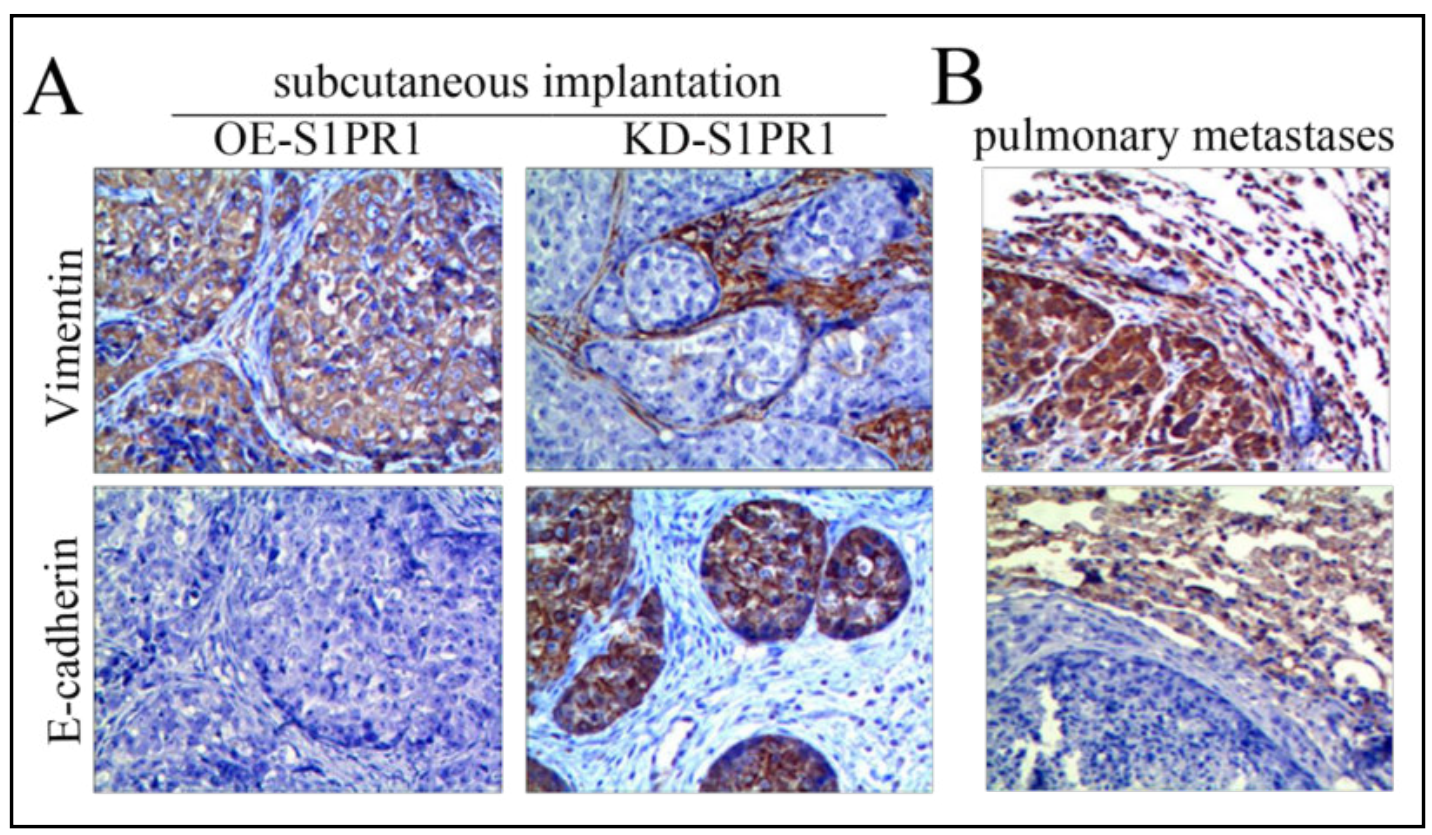

Fig. 10. IHC for EMT markers in subcutaneous implantation and pulmonary metastases. a. Vimentin staining and E-cadherin staining for tumors from the subcutaneous implantation of OE-S1PR1 group (left) and the KD-S1PR1 group (right) b. Pulmonary metastases with vimentin positive (top) and E-cadherin negative staining (bottom); Magnification: $\times 400$.

Using cell line models of over-expression and under-expression of Gal-1 and S1PR1, we found that overexpression of Gal-1 in GC cells increases S1PR1 expression and promotes invasion. In contrast, silencing Gal-1 impaired invasiveness, and decreased S1PR1 expression. Furthermore, our study confirms that Gal-1 over-expression in GC can promote the expression of S1PR1. Rescue of S1PR1 expression in the context of Gal-1 knockdown restored invasive ability of MGC-803 cells, suggesting that Gal-1 induced expression of S1PR1 promotes invasion of GC.

Gal-1 acts as a scaffold protein for intracellular signaling pathways, and participates in protein-protein interactions with H-Ras [12]. H-Ras activation of MEK-ERK signaling results in phosphorylation of STAT3 on S727 [35,36]. It has also been reported that STAT3 regulated expression of S1PR1. Not only can STAT3 mediate S1PR1 expression, but S1PR1 activates STAT3 through the Jak2 tyrosine kinase $[24,37,38]$. We speculate that Gal-1 activates S1PR1 via activation of an "H-Ras - MEK/ERK -STAT3/S1PR1" axis in GC.

EMT is a process where epithelial cells transition into cells with mesenchymal phenotypes characterized by lost cellular polarity and adhesion, enhanced invasion and migration, and resistance to chemotherapy properties, and numerous studies have implicated EMT in aggressiveness of GC [39-44]. In this study, we observed that S1PR1 expression is elevated in a TGF- $\beta 1$ induced EMT model, and that knockdown of S1PR1 in MGC-803 cells reduces the EMT response and decreases invasion induced by TGF- $\beta 1$. This suggests a possible mechanism by which S1PR1 promotes invasion in GC cells through EMT. GC EMT is modulated by diverse intracellular cues, and can be triggered by various transcription factors, activation of numerous signaling pathways, such as the Ras-MAPK, PI3K/AKT, Wnt, Src, Hedgehog, or Rho pathways [45, 46] S1PR1 may activate the "Jak/STAT3-Src" axis [38] [47], which can in turn induce GC EMT. However, the specific mechanism of action merits further exploration. To further confirm the correlation between S1PR1 and EMT signatures, we examined E-Cadherin and vimentin in GC tumor tissue by IHC. We found that EMT was associated with GC metastasis, and that S1PR1 maycontribute to the metastatic process. We report similar results in our in vivo study, where S1PR1 expression promoted GC invasion

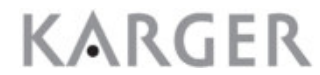




\section{Cellular Physiology Cell Physiol Biochem 2018:51:11-30 and Biochemistry \begin{tabular}{l|l} 
DOI: 10.1159/000495157 & $\begin{array}{l}\text { (c) } 2018 \text { The Author(s). Published by S. Karger AG, Basel } \\
\text { www.karger.com/cpb }\end{array}$
\end{tabular}}

You et al.: Galectin-1 Promotes GC Metastasis

and pulmonary metastasis, and over-expression of S1PR1 was related to EMT biomarkers, indicating that S1PR1 promotes GC invasion and metastasis by activating EMT.

\section{Conclusion}

We elucidated a novel mechanism by which Gal-1 promotes invasion and metastasis in GC through an enhanced expression of S1PR1. Moreover, we demonstrated that S1PR1 enhances invasion and metastasis of GC through the promoting EMT. The findings suggest that Gal-1 and S1PR1 may potentially be therapeutic targets for GC.

\section{Acknowledgements}

This work was supported in part by China Postdoctoral Science Foundation (grant number 2018M632400), the National Natural Science Foundation of China (81172279 and 81572343).

\section{Disclosure Statement}

The authors declare they have no conflicts of interest.

\section{References}

$>1$ Torre LA, Bray F, Siegel RL, Ferlay J, Lortet-Tieulent J, Jemal A: Global cancer statistics, 2012. CA Cancer J Clin 2015;65:87-108.

-2 Ferlay J, Soerjomataram I, Dikshit R, Eser S, Mathers C, Rebelo M, Parkin DM, Forman D, Bray F: Cancer incidence and mortality worldwide: sources, methods and major patterns in GLOBOCAN 2012. Int J Cancer 2015;136:E359-386.

3 Cai L, Zheng ZL, Zhang ZF: Risk factors for the gastric cardia cancer: a case-control study in Fujian Province. World J Gastroenterol 2003;9:214-218.

4 Kubo A, Corley DA: Marked regional variation in adenocarcinomas of the esophagus and the gastric cardia in the United States. Cancer 2002;95:2096-2102.

5 Chen W, Zheng R, Zhang S, Zeng H, Xia C, Zuo T, Yang Z, Zou X, He J: Cancer incidence and mortality in China, 2013. Cancer Lett 2017;401:63-71.

6 Lee JH, Kim JG, Jung HK, Kim JH, Jeong WK, Jeon TJ, Kim JM, Kim YI, Ryu KW, Kong SH, Kim HI, Jung HY, Kim YS, Zang DY, Cho JY, Park JO, Lim DH, Jung ES, Ahn HS, Kim HJ: Clinical practice guidelines for gastric cancer in Korea: an evidence-based approach. J Gastric Cancer 2014;14:87-104.

7 Qu Y, Zhou C, Zhang J, Cai Q Li J, Du T, Zhu Z, Cui X, Liu B: The metastasis suppressor SOX11 is an independent prognostic factor for improved survival in gastric cancer. Int J Oncol 2014;44:1512-1520.

-8 Yang K, Choi YY, Zhang WH, Chen XZ, Song MK, Lee J, Zhang B, Chen ZX, Kim HI, Chen JP, et al: Strategies to improve treatment outcome in gastric cancer: a retrospective analysis of patients from two high-volume hospitals in Korea and China. Oncotarget 2016;7:44660-44675.

-9 Barondes SH, Castronovo V, Cooper DN, Cummings RD, Drickamer K, Feizi T, Gitt MA, Hirabayashi J, Hughes C, Kasai K, et al.: Galectins: a family of animal beta-galactoside-binding lectins. Cell 1994;76:597-598.

10 Vasta GR: Galectins as pattern recognition receptors: structure, function, and evolution. Adv Exp Med Biol 2012;946:21-36.

11 Camby I, Le Mercier M, Lefranc F, Kiss R: Galectin-1: a small protein with major functions. Glycobiology 2006;16:137R-157R.

12 Paz A, Haklai R, Elad-Sfadia G, Ballan E, Kloog Y: Galectin-1 binds oncogenic H-Ras to mediate Ras membrane anchorage and cell transformation. Oncogene 2001;20:7486-7493. 


\section{Cellular Physiology Cell Physiol Biochem 2018;51:11-30 and Biochemistry DOl: 10.1159/000495157 2018 O 2018 The Author(s). Published by S. Karger AG, Basel

13 Suzuki 0, Abe M: Galectin-1-mediated cell adhesion, invasion and cell death in human anaplastic large cell lymphoma: regulatory roles of cell surface glycans. Int J Oncol 2014;44:1433-1442.

14 Chen L, Yao Y, Sun L, Zhou J, Liu J, Wang J, Li J, Tang J: Clinical implication of the serum galectin-1 expression in epithelial ovarian cancer patients. J Ovarian Res 2015;8:78.

15 Carlsson MC, Cederfur C, Schaar V, Balog CI, Lepur A, Touret F, Salomonsson E, Deelder AM, Ferno M, Olsson $\mathrm{H}$, et al: Galectin-1-binding glycoforms of haptoglobin with altered intracellular trafficking, and increase in metastatic breast cancer patients. PLoS One 2011;6:e26560.

16 Tang D, Zhang J, Yuan Z, Gao J, Wang S, Ye N, Li P, Gao S, Miao Y, Wang D, Jiang K: Pancreatic satellite cells derived galectin-1 increase the progression and less survival of pancreatic ductal adenocarcinoma. PLoS One 2014;9:e90476.

17 Zhou X, Li D, Wang X, Zhang B, Zhu H, Zhao J: Galectin-1 is overexpressed in CD133+ human lung adenocarcinoma cells and promotes their growth and invasiveness. Oncotarget 2015;6:3111-3122.

18 Chen J, Zhou SJ, Zhang Y, Zhang GQ Zha TZ, Feng YZ, Zhang K: Clinicopathological and prognostic significance of galectin-1 and vascular endothelial growth factor expression in gastric cancer. World J Gastroenterol 2013;19:2073-2079.

19 He XJ, Tao HQ Hu ZM, Ma YY, Xu J, Wang HJ, Xia YJ, Li L, Fei BY, Li YQ, Chen JZ: Expression of galectin-1 in carcinoma-associated fibroblasts promotes gastric cancer cell invasion through upregulation of integrin beta1. Cancer Sci 2014;105:1402-1410.

20 Zheng L, Xu C, Guan Z, Su X, Xu Z, Cao J, Teng L: Galectin-1 mediates TGF-beta-induced transformation from normal fibroblasts into carcinoma-associated fibroblasts and promotes tumor progression in gastric cancer. Am J Transl Res 2016;8:1641-1658.

21 Lee MJ, Van Brocklyn JR, Thangada S, Liu CH, Hand AR, Menzeleev R, Spiegel S, Hla T: Sphingosine-1phosphate as a ligand for the G protein-coupled receptor EDG-1. Science 1998;279:1552-1555.

-22 Liu CH, Thangada S, Lee MJ, Van Brocklyn JR, Spiegel S, Hla T: Ligand-induced trafficking of the sphingosine-1-phosphate receptor EDG-1. Mol Biol Cell 1999;10:1179-1190.

23 Watters RJ, Wang HG, Sung SS, Loughran TP, Liu X: Targeting sphingosine-1-phosphate receptors in cancer. Anticancer Agents Med Chem 2011;11:810-817.

24 Lee H, Deng J, Kujawski M, Yang C, Liu Y, Herrmann A, Kortylewski M, Horne D, Somlo G, Forman S, et al: STAT3-induced S1PR1 expression is crucial for persistent STAT3 activation in tumors. Nat Med 2010;16:1421-1428.

25 Zhang L, Kim S, Ding W, Tong Y, Zhang X, Pan M, Chen S: Arsenic sulfide inhibits cell migration and invasion of gastric cancer in vitro and in vivo. Drug Des Devel Ther 2015;9:5579-5590.

-26 Deng J, Liu Y, Lee H, Herrmann A, Zhang W, Zhang C, Shen S, Priceman SJ, Kujawski M, Pal SK, et al: S1PR1STAT3 signaling is crucial for myeloid cell colonization at future metastatic sites. Cancer Cell 2012;21:642654.

27 He S, Liao G, Liu Y, Huang L, Kang M, Chen L: Overexpression of STAT3/pSTAT3 was associated with poor prognosis in gastric cancer: a meta-analysis. In Int J Clin Exp Med 2015;8:20014-20023.

-28 Wu LJ, Li HX, Luo XT, Lu RZ, Ma YF, Wang R, Zhang J, Yang DQ Yu H, Liu J: STAT3 activation in tumor cellfree lymph nodes predicts a poor prognosis for gastric cancer. Int J Clin Exp Pathol 2014;7:1140-1146.

29 Steinestel K, Eder S, Schrader AJ, Steinestel J: Clinical significance of epithelial-mesenchymal transition. Clin Transl Med 2014;3:17.

30 Lei X, Xu JF, Chang RM, Fang F, Zuo CH, Yang LY: JARID2 promotes invasion and metastasis of hepatocellular carcinoma by facilitating epithelial-mesenchymal transition through PTEN/AKT signaling. Oncotarget 2016;7:40266-40284.

31 Tian T, Li X, Hua Z, Ma J, Wu X, Liu Z, Chen H, Cui Z: S100A7 promotes the migration, invasion and metastasis of human cervical cancer cells through epithelial-mesenchymal transition. Oncotarget 2017;8:24964-24977.

-32 Uzilov AV, Ding W, Fink MY, Antipin Y, Brohl AS, Davis C, Lau CY, Pandya C, Shah H, Kasai Y, et al: Development and clinical application of an integrative genomic approach to personalized cancer therapy. Genome Med 2016;8:62.

-33 Csermely P, Korcsmaros T, Kiss HJ, London G, Nussinov R: Structure and dynamics of molecular networks: a novel paradigm of drug discovery: a comprehensive review. Pharmacol Ther 2013;138:333-408. 


\section{Cellular Physiology Cell Physiol Biochem 2018;51:11-30

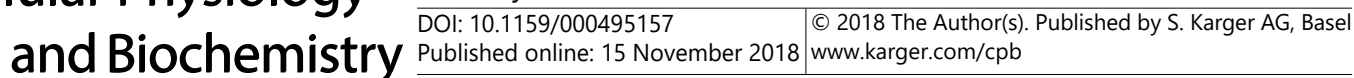

You et al.: Galectin-1 Promotes GC Metastasis

34 Chong Y, Tang D, Gao J, Jiang X, Xu C, Xiong Q Huang Y, Wang J, Zhou H, Shi Y, Wang D: Galectin-1 induces invasion and the epithelial-mesenchymal transition in human gastric cancer cells via non-canonical activation of the hedgehog signaling pathway. Oncotarget 2016;7:83611-83626.

-35 Gough DJ, Koetz L, Levy DE: The MEK-ERK pathway is necessary for serine phosphorylation of mitochondrial STAT3 and Ras-mediated transformation. PLoS One 2013;8:e83395.

-36 Chung J, Uchida E, Grammer TC, Blenis J: STAT3 serine phosphorylation by ERK-dependent and -independent pathways negatively modulates its tyrosine phosphorylation. Mol Cell Biol 1997;17:65086516.

-37 Lankadasari MB, Aparna JS, Mohammed S, James S, Aoki K, Binu VS, Nair S, Harikumar KB: Targeting S1PR1/STAT3 loop abrogates desmoplasia and chemosensitizes pancreatic cancer to gemcitabine. Theranostics 2018;8:3824-3840.

38 Priceman SJ, Shen S, Wang L, Deng J, Yue C, Kujawski M, Yu H: S1PR1 is crucial for accumulation of regulatory T cells in tumors via STAT3. Cell Rep 2014;6:992-999.

-39 Zhao J, Liu Y, Zhang W, Zhou Z, Wu J, Cui P, Zhang Y, Huang G: Long non-coding RNA Linc00152 is involved in cell cycle arrest, apoptosis, epithelial to mesenchymal transition, cell migration and invasion in gastric cancer. Cell Cycle 2015;14:3112-3123.

40 Huang L, Wu RL, Xu AM: Epithelial-mesenchymal transition in gastric cancer. Am J Transl Res 2015;7:21412158.

41 Li J, Deng Z, Wang Z, Wang D, Zhang L, Su Q Lai Y, Li B, Luo Z, Chen X, et al: Zipper-interacting protein kinase promotes epithelial-mesenchymal transition, invasion and metastasis through AKT and NF-kB signaling and is associated with metastasis and poor prognosis in gastric cancer patients. Oncotarget 2015;6:8323-8338.

42 Huang D, Duan H, Huang H, Tong X, Han Y, Ru G, Qu L, Shou C, Zhao Z: Cisplatin resistance in gastric cancer cells is associated with HER2 upregulation-induced epithelial-mesenchymal transition. Sci Rep 2016; 6:20502.

43 Peng Z, Wang CX, Fang EH, Wang GB, Tong Q: Role of epithelial-mesenchymal transition in gastric cancer initiation and progression. World J Gastroenterol 2014;20:5403-5410.

44 Xu Z, Zheng G, Wang Y, Zhang C, Yu J, Teng F, Lv H, Cheng X: Aqueous Huaier Extract Suppresses Gastric Cancer Metastasis and Epithelial to Mesenchymal Transition by Targeting Twist. J Cancer 2017;8:38763886.

45 Lamouille S, Xu J, Derynck R: Molecular mechanisms of epithelial-mesenchymal transition. Nat Rev Mol Cell Biol 2014, 15:178-196.

46 Sen B, Johnson FM: Regulation of SRC family kinases in human cancers. J Signal Transduct 2011;2011:865819.

-47 Park J, Kim S, Joh J, Remick SC, Miller DM, Yan J, Kanaan Z, Chao JH, Krem MM, Basu SK, et al: MLLT11/AF1q boosts oncogenic STAT3 activity through Src-PDGFR tyrosine kinase signaling. Oncotarget 2016;7:4396043973. 